BULLETIN Bulletin hispanique

HISPANIQUE Université Michel de Montaigne Bordeaux

115-1 | 2013

Poésie et société en Espagne : 1650-1750

\title{
Rodrigo Cacho Casal, La esfera del ingenio. Las silvas de Quevedo y la tradición europea
}

Biblioteca Nueva, Madrid, 2012

\section{Mercedes Blanco}

\section{(2) OpenEdition}

\section{Journals}

Edición electrónica

URL: http://journals.openedition.org/bulletinhispanique/2581

DOI: 10.4000/bulletinhispanique.2581

ISSN: $1775-3821$

\section{Editor}

Presses universitaires de Bordeaux

\section{Edición impresa}

Fecha de publicación: 1 junio 2013

Paginación: 371-377

ISBN: 978-2-86781-898-1

ISSN: 0007-4640

Referencia electrónica

Mercedes Blanco, «Rodrigo Cacho Casal, La esfera del ingenio. Las silvas de Quevedo y la tradición europea », Bulletin hispanique [En línea], 115-1 | 2013, Publicado el 06 diciembre 2013, consultado el 23 septiembre 2020. URL : http://journals.openedition.org/bulletinhispanique/2581 ; DOI : https://doi.org/ 10.4000/bulletinhispanique.2581

Este documento fue generado automáticamente el 23 septiembre 2020.

Tous droits réservés 


\title{
Rodrigo Cacho Casal, La esfera del ingenio. Las silvas de Quevedo y la tradición europea
}

Biblioteca Nueva, Madrid, 2012

\author{
Mercedes Blanco
}

\section{REFERENCIA}

Rodrigo Cacho Casal, La esfera del ingenio. Las silvas de Quevedo y la tradición europea, Madrid, Biblioteca Nueva, 2012, 264 p.

1 Además de dos sólidas aportaciones acerca de La poesía burlesca de Quevedo y sus modelos italianos (Santiago, 2003) y sobre Dante y Quevedo: la «Divina Commedia» en los «Sueños» (Manchester, 2003), junto con una edición en prensa de la segunda parte de Política de Dios, el joven autor de este libro tiene en su haber una nutrida serie de valiosos artículos, sobre Quevedo poeta y sobre otros muchos aspectos de la poesía áurea. En estos trabajos, Rodrigo Cacho aprovecha con talento y diligencia las bazas que debe a su trayectoria personal y académica, reuniendo en afortunada síntesis lo mejor del hispanismo de varios países: dominio impecable del italiano y del inglés, y familiaridad con las fuentes y la bibliografía en dichos idiomas; sólida formación filológica dispensada en uno de los mejores centros universitarios españoles, Santiago de Compostela; destreza retórica y pedagógica adquirida por el ejercicio de la docencia y de la investigación en universidades inglesas y canadienses y por el trato con los estudiantes exigentes y estimulantes a quienes le toca hoy formar en Cambridge.

Resaltan como nunca estos méritos en la obra que nos ocupa. Titulado La esfera del ingenio. Las silvas de Quevedo y la tradición europea, este libro de tamaño manejable y de precio asequible se presenta como una cima de la investigación de Rodrigo Cacho sobre el escritor y a la vez una despedida a su período de dedicación a él. Esto último el lector lo lamentará seguramente, porque leyendo La esfera del ingenio se aprende mucho, pero 
también se disfruta como ocurre rara vez con la prosa académica. Da cierta pena que el libro sea un adiós a Quevedo, cuando revela un dominio perfecto del tema logrado por una labor tenaz y metódica.

3 Y sin embargo, la despedida es como en los toreros, un desafío y un compromiso de hacer una faena redonda y como diría Gracián, plausible, digna de aplauso. Es una de las condiciones que han hecho posible un libro personalísimo, y que concilia ingeniosamente los opuestos: una obra breve y una suma; una lectura morosamente analítica de un número limitado de textos y una visión general de un Quevedo posible, uno de los más interesantes; un libro sesudo y erudito, muy respetable académicamente, y un ensayo inspirado, no pocas veces líricamente arrebatado. Todo esto lo convierte en un libro de todas horas, como es «hombre de todas horas» el discreto forjado por Gracián, y a él nos podemos volver en busca de buena filología, pero también cuando vamos a caza de ideas, o, simplemente, deseamos que la crítica contribuya a hacernos gustar de la poesía.

4 Puesto que la introducción es más bien una especie de captatio benevolentiae, el libro empieza de verdad con un capítulo I, 1 «Conceptismo y modernidad poética», que vale como introducción teórica no sólo al estudio de las silvas, sino a toda la poética de Quevedo y de su tiempo. La visión del conceptismo que en él propone Rodrigo Cacho se basa en su lectura personal de Gracián (obviamente apuntalada con otras muchas lecturas, antiguas y modernas) y en el brillante análisis de unos cuantos ejemplos tomados de la literatura burlesca y moral de Quevedo. Los pilares en que se asienta esta teoría son las ideas de "velocidad» y de "esfera del ingenio» siendo esta última, la más original, inspirada en la definición que da Gracián del «concepto por correspondencia y proporción», punto de arranque de toda la doctrina del jesuita sobre la agudeza. Esta definición empieza así: «Es el sujeto sobre quien se discurre y pondera [...] uno como centro, de quien reparte el discurso líneas de ponderación y de sutileza a las entidades que lo rodean...». De este pasaje extrae Cacho la metáfora "esfera del ingenio» que es el foco de su libro y que le da título. En esas entidades que «rodean» al sujeto (el tema de que se habla) y «adjuntos que lo coronan», él ve un «sistema astronómico conceptuoso donde no hay ni un solo elemento que permanezca aislado», puesto que cada "adjunto» es susceptible de convertirse en centro de un nuevo sistema planetario de adjuntos, de un nuevo concepto.

5 Puede que flaquee un poco el fundamento de esta metáfora en el texto de Gracián, puesto que al hablar de esos adjuntos o entidades, que «rodean» al sujeto sobre el que «se discurre y pondera», está manejando el jesuita nociones aprendidas en la lógica y dialéctica que enseñaban las escuelas, procedentes de las listas de predicables y de categorías aristotélicas. Estos predicables no tienen motivos, si nos atenemos al texto, de situarse en una esfera, y no en cualquier otra figura geométrica, plana o de tantas dimensiones como se quiera, con tal de que ésta admita un «centro».

6 Pero no hilemos tan delgado; aunque tal vez más imaginada que leída en Gracián, la «esfera del ingenio» posee un innegable valor heurístico puesto que gracias a ella aparecerá la coherencia de un gran número de fenómenos. Ya de entrada, le permite a Cacho conectar el conceptismo con todo el paradigma epistemológico de su tiempo.

7 En principio esta esfera del ingenio, centrada en el sujeto, parece remitir al universo cerrado de Aristóteles y de Ptolomeo, y a esa «episteme» que sobrevive hasta el siglo XVI, para la cual saber es lo mismo que reconocer las semejanzas inscritas en las cosas, según sostuvo Foucault en su famoso libro de 1966, Les mots et les choses. Es como si en 
torno a cada cosa sobre la que nos proponemos «discurrir», pensar y hablar, el mundo se reconstituyera como lo que es: un tejido de relaciones armónicas y significativas, de «correspondencias». El escritor ingenioso halla esas «correspondencias» desplegando lo que está implicado en el lenguaje, un lenguaje que le pertenece a él pero que también pertenece a las cosas, puesto que el lenguaje y el mundo no están todavía separados. El mundo habla a través de las signaturas; el cosmos esférico tiene su perfecto correlato en el microcosmos y éste puede girar en torno a cualquier «sujeto».

embargo, progresando en su examen de la mentalidad «conceptista», Rodrigo Cacho se da cuenta de que a ésta le es por completo ajena la creencia en la maciza realidad de un mundo regido por las correspondencias. Al contrario, Gracián, Quevedo y otros autores de su tiempo, con talante escéptico, desconfían de las evidencias dictadas por el lenguaje, y tienden a desmontarlas o a desnaturalizarlas, dando a ver por ejemplo que el lenguaje es plural y heterogéneo y que se descompone en una serie de códigos convencionales, uno de ellos el "poético», códigos que no se armonizan sino que suelen ignorarse y cuyo acercamiento produce el choque del chiste y de la paradoja. El concepto mismo no es fruto de una empresa cognitiva, sino que resulta de un hallazgo artístico, de una creación que suplanta a la divina o al menos la suplementa. De ello Rodrigo Cacho deduce su «modernidad» aunque, siguiendo a Foucault, habría que hablar más bien de su parentesco con la episteme "clásica» que sucede a la del Renacimiento, para ser a su vez abandonada en el siglo XIX. La episteme clásica se caracteriza en primer lugar por la agresiva ruptura con las «semejanzas», cuyos documentos más radicales encuentra Foucault en la obra de Descartes y en el Quijote.

Sea como fuere, la «esfera del ingenio» no hace referencia al cosmos esférico como creación divina, ni al microcosmo que lo duplica, sino a un universo artificial, fábrica caprichosa del artista humano. El concepto presenta del objeto al que hace referencia («el sujeto») un modelo ficticio a sabiendas en que las correspondencias, proporciones, armonías y semejanzas se «exprimen», como escribe Gracián, se sacan a la fuerza, se inventan, «a la ocasión», de manera circunstancial y momentánea. Esta esfera gira sobre sí misma pero también se desplaza a medida que avanza el discurso, deslizándose, disolviéndose y rehaciéndose sin cesar. Por su carácter de juego y de virtuosismo, es, más que una esfera, una burbuja, o una peonza o perinola: o sea un objeto muy quevediano que asoma en textos humorísticos como la «mujer puntiaguda con enaguas», que puede ser una "peonza al revés», o en La Perinola, la más amplia y más graciosa de las sátiras literarias de Quevedo. En suma, menos que plantear una nueva configuración epistemológica, el conceptismo, que es un gran momento para la literatura y el arte, se sustenta en el espacio vacante entre el reinado de las semejanzas y la episteme clásica que se establecerá sobre sus ruinas, y sabe vivir en el aire, en un momento de crisis y encrucijada. De ahí la «velocidad»: la rapidez vertiginosa de esas «líneas de ponderación y de sutileza» trazadas por el ingenio, y el dinamismo inquieto de un pensamiento que hace que la peonza se mantenga en pie, que vuele la flecha, y que el planeta se mantenga (más o menos) en su órbita.

10 Todo esto y mucho más es lo que sugiere la metáfora propuesta por Cacho, y que a él le sirve de plataforma desde la cual contemplar con altura un tema más modesto pero no menos apasionante: el de las silvas de Quevedo, a cuyo conjunto dedica el segundo capítulo de la primera parte. Los cuatro capítulos de que consta la segunda llevan a cabo cada uno el examen detenido de una silva: Al pincel («Tú, que en cuerpo pequeño»); 
Contra la artillería «¿En cárcel de metal, ¡oh atrevimiento»; Himno a las estrellas; ( $\mathrm{A}$ vosotras, estrellas...»); Roma antigua y moderna («Esta que miras grande Roma ahora»).

11 Acerca de las silvas «en la trayectoria» de Quevedo el libro de Rodrigo Cacho sintetiza y supera los estudios de Eugenio Asensio, Pablo Jauralde, Carmen Rocha de Sigler, Manuel Ángel Candelas Colodrón y Alfonso Rey ${ }^{1}$. Consigue demostrar la voluntad firme y constante que tuvo Quevedo de crear un nuevo género en la poesía castellana, de darle el nombre de silva, y de asentar mediante esta invención su fama de poeta, voluntad reconocida por varios escritores de su tiempo, y aplaudida por Lope de Vega. Quevedo vincula este género de modo no exclusivo con la fórmula métrica llamada "silva», alternancia libre de endecasílabos y heptasílabos con rimas libremente distribuidas. Le asigna una total libertad en la forma y una completa versatilidad del contenido, jugando con lo que la palabra implicaba de crecimiento irregular y espontáneo, de fecundidad no domada, por su asociación verbal con la silva como bosque, y por vindicar como modelo el género romano inventado por Estacio en tiempos de Domiciano, a finales del siglo I d.C.

La imagen que nos da Rodrigo Cacho de Quevedo es la de un hombre que se quiere y se sabe ante todo poeta, y, que ya lo vea como bendición o humorísticamente como maldición, entrega a la poesía lo mejor de sí mismo y quiere ser recordado por ella. Dentro del vasto monumento poético que Quevedo va edificando desde sus años de estudiante, pero que la muerte le impedirá concluir, las silvas constituyen una pieza de suma importancia. La idea de que el poeta quiso incluir en su Parnaso español un «libro de silvas», la comparte Rodrigo Cacho con su maestro Alfonso Rey, para quien «los indicios disponibles sugieren que Quevedo fue expandiendo ese núcleo original de siete poemas [el que aparece en las Flores de Calderón], al tiempo que emprendía la revisión estilística de cada uno [...] teniendo como objetivo final un verdadero libro de silvas»².

Pero, mientras que Rey afirma que «no podemos reconstruir ese proceso», Cacho se esfuerza por reconstruirlo, al menos en parte, y en ese proceso de reconstrucción es instrumento precioso la lectura atenta de cuatro silvas, que componen la segunda parte del libro. Según él, Quevedo concibe el proyecto de las silvas en su fase de cultivo juvenil de las humanidades. Hay indicios de que fue a raíz de sus desvelos de aprendiz de helenista sobre las Anacreónticas y sobre el seudo-Focílides, cuando surgió la idea de escribir una colección de silvas, una «unidad en movimiento». de que tendrán noticia en la década siguiente hombres como Bartolomé Jiménez Patón y Lope de Vega. Siete poemas de Quevedo, seis de los cuales más tarde llevarán el marbete de silva, figuran uno tras otro ya en las Flores de poetas de Juan Antonio Calderón (ms. que lleva fecha de 1611) ${ }^{3}$ y doce se conservan en un manuscrito de Évora, que debe de ser contemporáneo del viaje de Quevedo a Italia. Durante el período italiano, de 1613 a 1619, y bajo el doble estímulo de la gran cultura humanística de la Italia de entonces y de las atractivas novedades de Giambattista Marino, Quevedo reelabora sus silvas ya escritas y añade otras, de lo que queda constancia en un famoso manuscrito en parte autógrafo (ms. XIV E. 46 de la Biblioteca Nazionale de Nápoles), que ya contiene una colección de veintisiete silvas. Una carta a su amigo el obispo Juan de la Sal, de 1624, atestigua que todavía trabajaba por entonces en su colección de silvas, y da a sentir lo ilusionado que estaba con ellas. El siguiente testimonio, póstumo, es el de las Tres musas últimas castellanas de 1670, que recoge los textos del manuscrito de Nápoles, revisados con mayor o menor profundidad, y los asocia con otros tres. La idea de un trabajo de varias décadas, al que el poeta daba una importancia especial, parece pues imponerse. Hay incluso indicios 
tenues, pero que agrupados tienen fuerza probatoria, de que esta colección en movimiento es para Quevedo una parte de sí mismo, un alivio de esa melancolía que nombra en la carta a Juan de la Sal ${ }^{4}$, a la que va y vuelve a ratos como Penélope a su tela, puliendo algunos textos, en otros añadiendo y quitando, según va cambiando su estado de ánimo y para dar cabida a nuevas experiencias y opiniones.

La detenida lectura que dedica Rodrigo Cacho a cuatro silvas en los cuatro capítulos de la segunda parte, revisión de estudios que ha publicado los últimos años (citados en nota p. 18), permite enlazar la introducción teórica sobre el ingenio y el estudio de las silvas. En la Silva al pincel tenemos, como Cacho deja claro, un texto juvenil al que Quevedo volvió una y otra vez, limándolo y ajustándolo a una experiencia cambiante de la pintura, hasta finales de la década de 1630, cuando ya estaba familiarizado con el estilo «veneciano» de Velázquez. Como Asensio fue el primero en ver, el poema empezó sin duda como reescritura de una oda de Rémy Belleau (Le pinceau) ${ }^{5}$, a su vez inspirada en una oda anacreóntica. El poema de Belleau es una bellísima composición cerrada, elipsis con dos focos, elogio de la dama por un lado, del pintor Georges Bombas por otro lado, a quien el poeta pide un retrato de su maitresse. Contiene expresiones ingeniosas que amalgaman la acción pintada y la acción de pintarla: así el pincel no representa el fuego que destruyó a Troya, sino lo enciende de nuevo («rallumant le feu devant Troie»), y se vuelve puñal indoloro cuando pinta la herida de Lucrecia. Estas figuras, que hacen patente la perfecta actualidad que cobran las acciones y pasiones de los héroes en su imagen pictórica, y las acciones del pintor en su representación poética, fueron sin duda lo que más apreció Quevedo en Belleau y el motivo de que emprendiera su reescritura. Pero el texto de Quevedo es una silva, es decir una obra abierta, una meditación que no tiene por qué cerrarse mientras el autor sienta deseos de decir algo sobre la pintura, sobre el arte, sobre los artistas de su tiempo y de su patria.

El pincel, «cuerpo pequeño» capaz de engendrar un mundo, de anular las distancias, de resucitar a los muertos, de dar ser a lo imaginado y fabuloso, de hacer revivir cuantos afectos y dramas ha conocido la humanidad, es figura del ingenio. Meditar sobre el pincel es al propio tiempo discurrir sobre el arte poética. La lectura de la silva que propone Cacho desvela con minuciosa pericia las sutiles alusiones que contiene la silva a las cuestiones candentes del arte de la pintura. Pero sobre todo demuestra que, bajo aparentes lugares comunes, la silva expresa una postura estética coherente. Quevedo gusta de los retratistas y coloristas, como Tiziano, y en el gran debate de éstos con los partidarios del diseño (de una pintura científica, basada platónicamente en las matemáticas y en la contemplación de las ideas), toma claramente partido por los primeros. Lo importante para el arte es desafiar la muerte, dar a ver como presente lo ausente y lo pasado, y ello con medios ingeniosos, es decir oblicuos e indirectos, aparentemente inadecuados: haciendo existir el color y la luz sin usar otra cosa que el carbón y el plomo, como Pacheco o Villarfañe, convocando a un ser más vivo que la vida misma al conjuro de indescifrables manchas y borrones, como Velázquez, o haciendo aparecer un «semblante distinto», una semejanza perfecta, en un laberinto de líneas trazadas con vertiginosa rapidez y a dos manos, como Morante. Es pues el prodigio técnico, la exhibición de la materialidad de los medios, los rasgos y lazos, los borrones, junto con la eficacia mágica, vital, del resultado, lo que debe alabarse en la pintura y lo que hace del pincel un perfecto símbolo del artista ingenioso.

16 Su contra-símbolo reside en el arma de fuego, cuya potencia destructiva «execra» la silva Contra la artillería, otro poema sin duda de la época italiana, interesante por el 
complejo trabajo intertextual, que desde una canción de Marino «Il ferro», publicada en la segunda parte de sus Rime (1602), se remonta a sus fuentes, Horacio y Ariosto, y opone la perennidad del ingenio poético, gracias al cual se dan las manos lo antiguo y lo moderno, a un ingenio artillero que no sólo mata, destroza y asuela, sino que alza una impenetrable frontera entre el antiguo valor y el empleo brutal de la fuerza propio de la guerra moderna.

También de un poema entonces reciente de Marino parte la tercera silva comentada en el libro, el Himno a las estrellas, que deja oír algunos ecos del Polifemo gongorino. Pero este texto, que Cacho fecha con buenas razones en el primer período italiano de Quevedo (poco después de 1613) aspira a parecerse nada menos que a los himnos órficos, que se creían entonces de remotísima antigüedad, inspirándose en la reelaboración de este modelo, a finales del siglo XV, por Michele Marullo, el griego italianizado nutrido de neoplatonismo florentino. El bello poema de Quevedo es resueltamente pagano en su ambientación y su sentimiento, y pretende, de modo tal vez juguetón pero también desafiante, restaurar en castellano la arcana sublimidad de los orígenes de la poesía, cuando el poeta oficiaba de mediador con las potencias celestes, propósito no sin afinidad con el de Góngora, casi por las mismas fechas, en el Polifemo y Soledades.

También a propósito de la última de las silvas de que se ocupa el libro, Roma antigua y moderna, lleva a cabo Cacho un minucioso análisis del entramado intertextual. La caprichosa libertad formal resalta aquí de forma notable puesto que los catorce primeros versos de la silva forman un soneto, imitación de Du Bellay (Antiquités de Rome, 18) y convierten esta forma cerrada en la apertura de una silva métrica de ciento ochenta versos. Quevedo deja ver que el soneto, con un concepto único, puede a la vez conservarse y resolverse en una forma abierta, como la silva, donde los conceptos se encadenan en curvas y espirales formando una esfera ingeniosa, objeto paradójico, cuyo dinamismo acaba borrando sus límites, más cometa que estrella. El soneto de Du Bellay, "Ces grands monceaux pierreux, ces vieux murs que tu vois», contrasta la grandeza ruinosa de la Roma antigua, como dueña del mundo, con sus humildes orígenes arcádicos y pastorales, pero concluye con una agudeza satírica, declarando que la Roma moderna ha regresado a esos humildes comienzos, instalando a su cabeza de nuevo un "pastor», el Pontífice, responsable de su ruina ("fatal à cette terre») como para mostrar que todo vuelve a donde empezó («montre que tout retourne à son commencement»). En cambio en la silva de Quevedo, coexisten varios marcos cronológicos, y «todo ocurre a la vez». De modo brillante, Cacho enlaza esta extraña ubicuidad temporal con una fantasía de Freud en El malestar en la cultura (1930). En el inconsciente todo el pasado se conserva incólume, como si en Roma se alzaran a la vez el Panteón de Agripa y el de Adriano, el templo a Minerva y la iglesia a Santa María sobre él edificada. Esta Roma fantaseada por un Freud con aficiones arqueológicas, figura imposible de la memoria inconsciente donde nada se destruye, no es ajena a la Roma de Quevedo que es a la vez todas las Romas de la memoria escrita por los poetas e inscrita en lugares y piedras, simultáneamente presentes en una ciudad-archivo, donde todo se conserva en su pequeñez, en su grandeza y en su ruina, y todo, como el Tíber, fluye y permanece. La silva, expansión del soneto francés, por el que empieza y al que termina volviendo, lo refuta afirmando la asunción triunfante de la historia de Roma en la modernidad de la Roma papal; en el Capitolio restaurado por Miguel Ángel, con el emperador filósofo 
Marco Aurelio cabalgando en su cima, y en la nave de la Iglesia, que no espera inmóvil que el tiempo la desgaste, sino que va hendiendo sus aguas con arrojo militante.

Un poco como Roma, las silvas de Quevedo se nos revelan, gracias a Rodrigo Cacho, como un lugar fuera del tiempo, tanto para su autor que en ocasiones las comunicó como terminadas y sin embargo nunca terminó de deshacerlas y rehacerlas, como para el lector, que las adivina y las rescata a través de ruinas y fragmentos.

Sin unidad temática, oscilando entre cualquier modelo estrófico y el libre decurso irregular de la silva métrica, las indefinidas silvas existen por referencia a una voluntad subjetiva de estilo, con la que Quevedo en último término se identifica. Como muestra espléndidamente Cacho, son laboratorio en que el ingenio convierte cada «sujeto», cada asunto, en el centro de un universo donde confluyen las voces de los antiguos y la intrépida novedad.

\section{NOTAS}

1. Eugenio Asensio, «Un Quevedo incógnito: las silvas», Edad de oro 2, 1983, p. 13-48; Pablo Jauralde Pou, «Las silvas de Quevedo», La silva, ed. B. López Bueno, Sevilla, Universidades de Sevilla y Córdoba, 1991, p. 163-172; Carmen Rocha de Sigler (ed.), Francisco de Quevedo, Cinco silvas, Salamanca, Universidad de Salamanca, 1994; Manuel Ángel Candelas-Colodrón, Las silvas de Quevedo, Vigo, Universidad de Vigo, 1997; Alfonso Rey, «La colección de silvas de Quevedo: propuesta de inventario», Modern Language Notes, 121, 2006, p. 99-118.

2. Alfonso Rey, art. cit., p. 260.

3. Flores de poetas de Juan Antonio Calderón. Año 1611, ed. y notas de J.M. Morata y J. de Dios Luque, Granada, Granada lingüística, 2009. <http://www.antequerano-granadinos.com/pv_obj_cache/ pv_obj_id_19045CEF709EB6FCC19F0BBB4F72619A615F8B00/filename/FLORES_ARNOprint.pdf>

4. «...yo volveré por mi melancolía en las silvas, en que el sentimiento y el estudio hacen algún esfuerzo por mí». (Carta a Juan de la Sal del 17 de junio de 1624), en Quevedo, Epistolario completo, ed. L. Astrana Marín, Madrid, Instituto Editorial Reus, 1946, p. 125-126)

5. Rémy Belleau, «Le pinceau», CEuvres complètes, Paris, 1867, I, p. 73-75.

\section{AUTORES}

\section{MERCEDES BLANCO}

Université de Paris Sorbonne - Paris IV 